Perfusion of the uterine junctional zone in nulliparous and primiparous women assessed by DCE-MRI, as a function of menstrual cycle and hormonal contraception

Peer-reviewed author version

MEYLAERTS, Liesbeth; Wijnen, L.; Bazot, M.; Grieten, M.; OMBELET, Willem \& VANDERSTEEN, Marjan (2017) Perfusion of the uterine junctional zone in nulliparous and primiparous women assessed by DCE-MRI, as a function of menstrual cycle and hormonal contraception. In: MAGNETIC RESONANCE IMAGING, 38, p. 101-111.

DOI: 10.1016/j.mri.2016.12.026

Handle: http://hdl.handle.net/1942/24175 


\section{PERFUSION OF THE UTERINE JUNCTIONAL ZONE IN NULLIPAROUS AND PRIMIPAROUS WOMEN ASSESSED BY DCE-MRI, AS A FUNCTION OF MENSTRUAL CYCLE AND HORMONAL CONTRACEPTION}

Magn Reson Imaging. 2017 May;38:101-111

\subsection{Abstract}

Purpose: To evaluate the perfusion parameters of inner and outer myometrium in healthy nulliparous and primiparous women who are and who are not currently using hormonal contraceptives by means of dynamic contrast-enhanced magnetic resonance imaging (DCE-MRI).

Material and methods: We performed pelvic 1.5T DCE-MRI on 98 women: 18 nulliparous non-users, 30 nulliparous users, 12 primiparous non-users and 38 primiparous users of hormonal contraception (mean age respectively 26.4, 25.8, 30.23 and 28.18 years). The nulliparous non-users underwent DCE-MRI investigations during their follicular, ovulatory and luteal phase. Perfusion parameters (iAUC/volume, $\mathrm{K}^{\text {trans }}, \mathrm{K}_{\mathrm{ep}}$ and $\mathrm{Ve}$ ) were assessed in the anterior and posterior wall of the junctional zone (JZ) and outer myometrium.

Results: In nulliparous non-users, the mean $\mathrm{K}^{\text {trans }}$ and $\mathrm{iAUC/volume}$ showed a decrease from follicular to luteal phase ( 0.82 vs $0.55 \mathrm{~min}^{-1}$ for $K^{\text {trans }}, \mathrm{p}=0 / 027$ and 1.28 vs 0.68 for iAUC/volume, $p<0.001)$. The anterior JZ demonstrated lower $K^{\text {trans }}(p=0.050)$ and higher $K_{e p}(p=0.012)$ in nulliparous non-users, lower $K^{\text {trans }}$ in nulliparous users $(p<0.001)$ and lower Ve in primiparous users $(p=$ 0.012 ) than the anterior outer myometrium. $K^{\text {trans }}$ in the anterior and posterior $J Z$ wall in nulliparous users was lower than in non-users $(p=0.001$ and $p=0.013$ ) and Ve at the anterior $\mathrm{JZ}$ wall in primiparous users was lower than in non-users $(p=0.044)$.

Conclusion: This study provides data on normal perfusion parameters of inner and outer myometrium, which may be potentially useful in assisted reproductive therapy. 
KEYWORDS: DCE-MRI - Perfusion - Junctional Zone - Outer Myometrium Nulliparous - Primiparous 


\subsection{Introduction}

The female reproductive system is characterized by rapid cyclic changes in blood flow throughout the menstrual cycle. During the female reproductive period, arteries present in the inner myometrium or junctional zone (JZ), supply the endometrium with oxygen and nutrients to contribute to endometrial growth. These arteries subsequently constrict in order to cause ischemia resulting in endometrial shedding during menstruation (1).

Recent ultrasonographic studies have demonstrated that inner myometrium perfusion is impaired in women with unexplained infertility (2). Other conditions of the reproductive system such as tumoral lesions, endometriosis, adenomyosis, abnormal severe menstrual bleeding and breakthrough bleeding are also associated with disturbances of the uterine angiogenic process and the vascular network (2-8). Microvascular parameter assessment could potentially be used to detect pathogenic conditions or in assisted reproductive therapy. This requires profound knowledge of the normal myometrial vasculature.

Dynamic contrast-enhanced magnetic resonance imaging (DCE-MRI) provides semi-quantitative assessment of perfusion kinetics, including perfusion assessment in myometrium (9). This non-invasive technique obtains repeated T1weighted MR images before, during and after a bolus injection of a contrast agent. Analysis of these images requires post-imaging processing with specialized software and physiological models. The software evaluates the signal enhancement resulting in the conversion of a signal intensity-time curve (10). Analysis of this curve, based on the model of Tofts (11) (figure 1), provides quantitative information about the perfusion parameters of the organ of interest. 


\section{Endothelium}

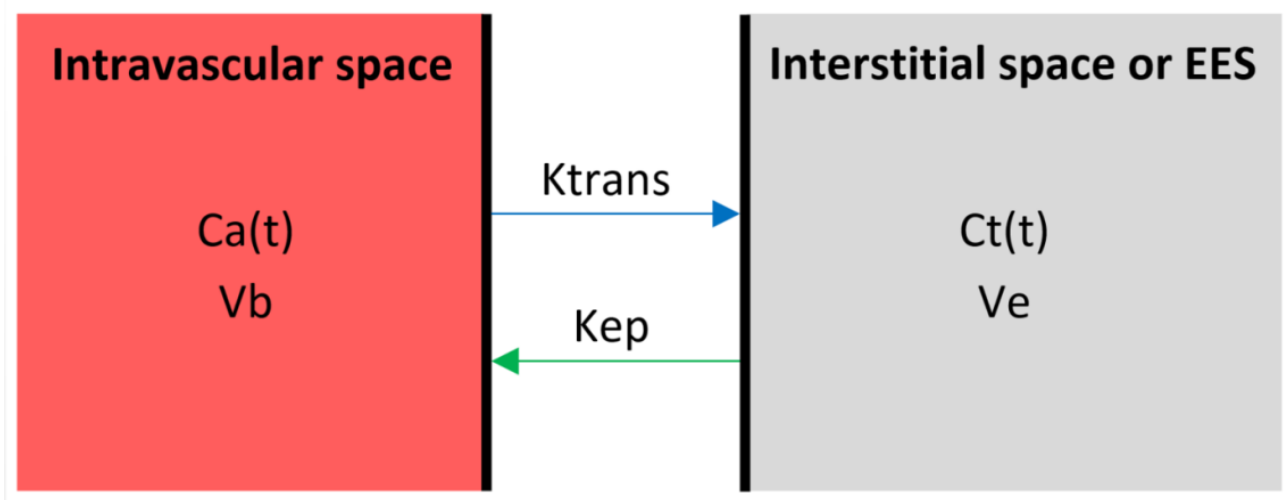

Figure 1: The assumptions used by dynamic contrast-enhanced magnetic resonance imaging (DCE-MRI) are based on the two compartment model of Tofts. Two compartments are assumed in this model: the intravascular space and the extracellular extravascular space (EES or interstitial space). The model provides information about the distribution of contrast agent across these compartments. Ca: arterial contrast agent concentration in function of time; Ct: tissue contrast agent concentration in function of time; $\mathrm{Vb}$ : whole blood volume per unit of tissue; Ve: total EES volume; $\mathrm{K}^{\text {trans }}$ : transfer constant; $\mathrm{K}_{\mathrm{ep}}$ : reflux constant.

The purpose of this prospective study is to investigate perfusion characteristics of normal JZ and outer myometrium throughout the menstrual cycle in a population of healthy nulliparous and primiparous women between 18 and 35 years old, by means of DCE-MRI. In addition, this study aims to detect whether or not the perfusion parameters are influenced by the menstrual cycle status, the use of hormonal contraceptives and the location in the uterine wall. 


\subsection{Material and Methods}

The study protocol was approved by the hospital ethics committee in order to perform this longitudinal study on volunteers (registration number 056). All included women provided a written informed consent and filled out an epidemiological questionnaire in order to obtain information regarding their birth date, height, weight, age at menarche, gestity and parity status and whether or not they currently smoke.

\subsubsection{Study population}

We included 48 volunteer nulliparous and 50 volunteer primiparous women at 6 to 12 months post-partum from December 2007 to January 2012. Recruitment was achieved by emailing and writing co-workers in our hospital, students and PhD students at the local university, personal contacts and cooperation with external physicians. Exclusion criteria were age less than 18 years or more than 35 years, non-Caucasian origin, pregnancy, medical history of infertility or a gynecological history such as heavy, prolonged or irregular menstrual periods, previous unknown uterine morphologic abnormality found on the first MRI examination, diminished renal function (assessed by creatinine levels collected prior to MRI investigation) and women with a pacemaker, clips or other MRIincompatible implanted devices.

Both the nulliparous and primiparous women were subdivided based on their use of hormonal contraception. Among the nulliparous women, 18 women were nonusers (mean age 26.4 years) and 30 women were users (mean age 25.8 years) of contraception therapy, and the group of primiparous women comprised 12 nonusers (mean age 30.23 years) and 38 users (mean age 28.18 years) of contraception therapy (figure 2). The different types of contraception therapy included oral contraceptive pills, progesterone-only implants, hormonal vaginal rings and intrauterine devices (table 1 ). 


\begin{tabular}{|l|l|l|l|l|l|l|}
\hline \multicolumn{2}{|l|}{} & $\begin{array}{l}98 \\
\text { women }\end{array}$ & \multicolumn{2}{l|}{} \\
\hline 48 nulliparous & & $\begin{array}{l}\text { 50 primiparous (6-12 months } \\
\text { post-partum) }\end{array}$ \\
\hline $\begin{array}{l}18 \text { non-users of hormonal } \\
\text { contraception }\end{array}$ & $\begin{array}{l}30 \text { users } \\
\text { sampled } \\
\text { randomly }\end{array}$ & & $\begin{array}{l}\text { 12 non-users of } \\
\text { hormonal } \\
\text { contraception }\end{array}$ & $\begin{array}{l}38 \text { users } \\
\text { sampled } \\
\text { randomly }\end{array}$ \\
\hline $\begin{array}{l}16 \\
\text { women } \\
\text { during } \\
\text { follicular } \\
\text { phase }\end{array}$ & $\begin{array}{l}\text { lumen } \\
\text { during } \\
\text { ovulatory } \\
\text { phase }\end{array}$ & $\begin{array}{l}17 \\
\text { women } \\
\text { during } \\
\text { luteal } \\
\text { phase }\end{array}$ & & $\begin{array}{l}7 \\
\text { women } \\
\text { during } \\
\text { follicular } \\
\text { phase }\end{array}$ & $\begin{array}{l}\text { women } \\
\text { during } \\
\text { luteal } \\
\text { phase }\end{array}$ & \\
\hline
\end{tabular}

Figure 2: Overview of the study population and the menstrual phases during which MRI examination was performed.

\subsubsection{Blood laboratory tests}

Blood samples were taken prior to each MRI examination in order to assess human chorionic gonadotrophin (hCG), creatinine, follicle-stimulating hormone (FSH), luteinizing hormone ( $\mathrm{LH})$, estradiol and progesterone levels. The follicular phase was considered around day 6-13 of the menstrual cycle, the ovulatory phase around day 14-16 and the luteal phase around day 17-28. The exact phase of the menstrual cycle was determined based on the hormone levels in all participants who did not use hormonal contraception.

\subsubsection{Magnetic Resonance Imaging}

DCE-MRI investigations were obtained with a 1.5T magnet unit (Siemens Magnetom Symphony Tim (4G-Dot upgraded), Erlangen, Germany; Software Syngo MR B15). The women were inserted with an intravenous catheter in the elbow crease. They were positioned on the table of the scanner in head-first supine position and an eight-channel receiver body array was placed on the pelvis. The MRI examination started with a localizer sequence followed by T2-weigthed turbo spin echo (T2 TSE) sequences without fat-suppression in transversal, coronal oblique in the long axis of uterine corpus and sagittal plane (repetition time/echo time: 5000-5100/88-89; flip angle: $180^{\circ}$; field of view: $320 \times 370 \mathrm{~mm}$; slice thickness: $5 \mathrm{~mm}$ with $1 \mathrm{~mm}$ intersection gap; and voxel size: 0.8-1.1 x 0.6-0.8 $\mathrm{x}$ 4-5 mm). In mutual agreement with the women, an intravenous injection of the 
abdominal-specific antispasmodic hyoscine butylbromide (buscopan, $1 \mathrm{ml}, 20$ $\mathrm{mg} / \mathrm{ml}$, Boehringer Ingelheim, Germany), diluted in sodium chloride $(10 \mathrm{ml}$, $0.09 \%$, Baxter, Lessines, Belgium) was administered in order to reduce bowel movements. Then, another sagittal T2 TSE image without fat suppression was obtained (repetition time/echo time: 4060-5610/89-93; flip angle: $180^{\circ}$; field of view: $360 \mathrm{~mm}$; slice thickness: $4 \mathrm{~mm}$ with $1 \mathrm{~mm}$ intersection gap; and voxel size: $0.9 \times 0.7 \times 4 \mathrm{~mm})$.

For DCE-MRI, perfusion acquisition consisted of a pre-contrast $T_{1}$ mapping at different flip angle (three acquisitions pre-contrast). Subsequently, intraveneouscontrast Gadoterate acid (Gd-DOTA, Dotarem) was administered at a rate of 3 $\mathrm{ml} / \mathrm{sec}$ followed by a flush of $10 \mathrm{ml}$ sodium chloride at an equal rate with an automatic injector (MEDRAD) (6). Then, dynamic series were acquired in the midsagittal plane of the uterus (in 2D FLASH or 3D FLASH). The scan parameters for 2D FLASH were: repetition time/echo time: 230/1.1 ms; time of acquisition: 3:04 min; flip angle: $15^{\circ}$; field of view: $400 \mathrm{~mm}$; 5 slices/slab; distance factor: $25 \%$; slice thickness: $10 \mathrm{~mm}$; number of measurements: 160; bandwidth: 1130 $(\mathrm{Hz} / \mathrm{Px})$; and voxel size: $2.6 \times 2.1 \times 10 \mathrm{~mm}$. The scan parameters for 3D FLASH were: repetition time/echo time: $3.66 / 1.23 \mathrm{~ms}$; time of acquisition: $5: 53 \mathrm{~min}$; flip angle: $20^{\circ}$; field of view: $360 \mathrm{~mm}$; $1 \mathrm{slab}$; distance factor: $20 \%$; slice thickness: $1.5 \mathrm{~mm}$; number of measurements: 29; bandwidth: $360(\mathrm{~Hz} / \mathrm{Px})$; and voxel size: $1.3 \times 0.9 \times 1.5 \mathrm{~mm}$.

All images were sent to a dedicated workstation.

The 18 nulliparous non-users of contraception were scheduled to undergo DCEMRI investigation during three phases of their menstrual cycle: follicular $(n=17)$, ovulatory $(n=17)$ and luteal $(n=16)$ phase. Due to practical considerations, three women underwent DCE-MRI, respectively, only during the follicular phase, follicular and ovulatory phase and ovulatory and luteal phase. This resulted in a total number of 50 examinations for the 18 nulliparous non-users of hormonal contraception. The 30 nulliparous users of contraception also underwent three DCE-MRI examinations during their cycle, which were not divided into the different phases because of the suppression by the contraceptive hormones. Two women underwent only two MRI investigations during their cycle, and one woman 
underwent only one MRI investigation. This resulted in a total number of 86 examinations for this group. The primiparous women acquired one DCE-MRI examination during their cycle on a random day (because of practical considerations concerning their newborn). Seven of the 12 primiparous women not using contraception were in their follicular phase at the time of DCE-MRI investigation and 5 women were in the luteal phase of their cycle.

\subsubsection{MR image analysis}

All measurements were performed on a specialized workstation (MMWP, Syngo MMWP VE36A) using the measuring cursor included in the workstation's software. The measurements were carried out consecutively by two independent investigators, a radiologist with 13 years of experience in pelvic imaging and a resident in radiology with three years of pelvic MRI experience. Both observers were blinded for the clinical information of the women (whether or not they were nulliparous or primiparous and non-users or users of hormonal contraception).

The $T_{2}$ TSE images obtained in the three anatomical planes before hyoscine butylbromide injection were first analyzed by the radiologist in order to detect possible suspicious findings of congenital or acquired uterine abnormalities. The corpus and cervix sizes latero-lateral ( $L L$, transverse) were measured on the coronal $T_{2}$ TSE image obtained before hyoscine butylbromide injection. The $T_{2}$ TSE sagittal image after hyoscine butylbromide injection without fat suppression was used to measure the length and antero-posterior (AP) size of the corpus (figure $3)$. The volume of corpus uteri was calculated using the formula for an ellipsoid: length $\mathrm{x}$ height $(\mathrm{AP}) \mathrm{x}$ width (LL) $\times 0.523(12)$.

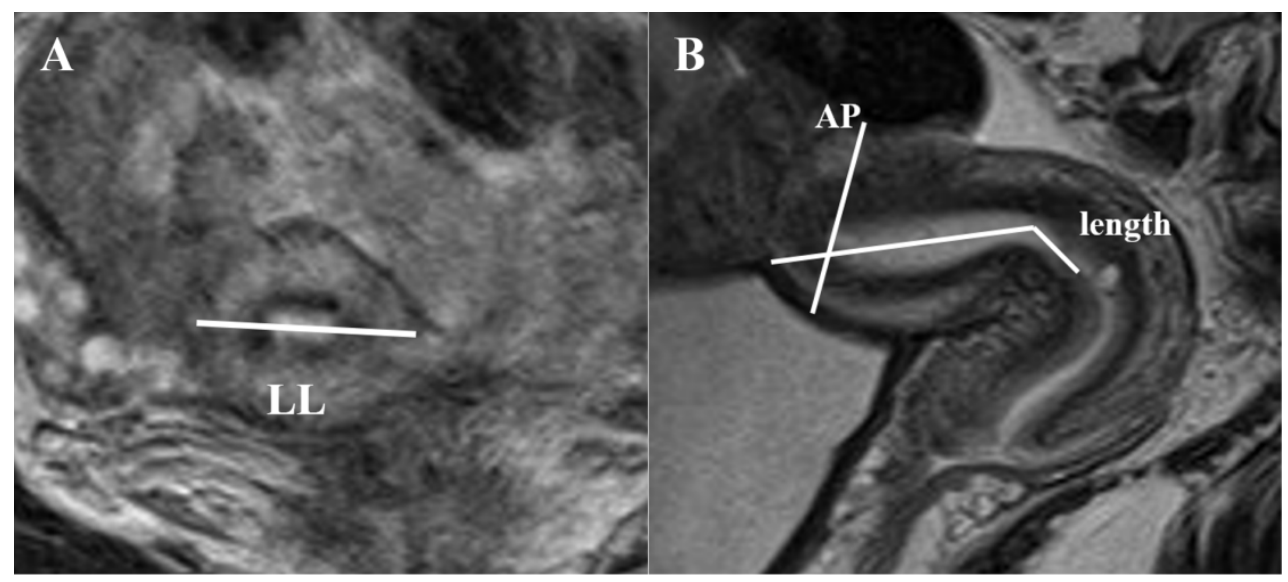


Figure 3: Dimensions measurements of the corpus uteri on sagittal and transversal magnetic resonance imaging (MRI). The sagittal T2-weighted MR image (B) was used to measure the antero-posterior (AP) uterine size and the length of the uterus, and the transversalT2 weighted image (A) was used to measure the latero-lateral (LL) uterine size.

The perfusion acquisitions were evaluated on Syngo Tissue 4D of Siemens. Two methods of evaluation were used: a quantitative method following the two compartment model of Tofts and a semi-quantitative evaluation method. The model of Tofts (11) comprises the following parameters: transfer constant $\left(K^{\text {trans }}\right)$, interstitial volume fraction (Ve) and reflux constant $\left(K_{e p}\right)$ (figure 1 ). The semiquantitative evaluation method retrieves the following parameters: Time-to-Peak (TTP), Arrival Time (AT) and initial Area Under the Curve in 60 seconds (iAUC). The perfusion parameters analyzed in this study are: iAUC (in correlation with the uterus/cervix volume), $K^{\text {trans }}, K_{e p}$ and $V e(9,10,13)$ (table 2 ).

Table 2: Description of the assessed perfusion parameters. EES: extravascular extracellular space.

\begin{tabular}{lll} 
Parameter & Description & Unit \\
\hline iAUC/volume & $\begin{array}{l}\text { Initial (first } 60 \text { seconds) area under the contrast agent concentration - } \\
\text { time curve after contrast administration. It is an indicator for the amount } \\
\text { of blood volume during the initial minute after the contrast agent enters } \\
\text { the blood per unit mass of tissue. IAUC is evaluated in correlation with the } \\
\text { volume of respectively the corpus or cervix uteri. }\end{array}$ \\
\hline $\mathrm{K}^{\text {trans }}$ & $\begin{array}{l}\text { Transfer constant, the influx of contrast agent from the blood plasma into } \\
\text { the EES, depends on capillary permeability, surface area and blood flow }\end{array}$ & min $^{-}$ \\
& per unit mass of tissue. & min $^{-}$ \\
& $\begin{array}{l}\text { Reflux constant, the efflux of contrast agent from the EES back into the } \\
\text { blood plasma. }\end{array}$
\end{tabular}

In order to measure these parameters, Regions Of Interest (ROIs), with a diameter of $1 \mathrm{~mm}$ were placed in post-processing software at different places: the anterior and posterior wall of the $\mathrm{JZ}$ and outer myometrium (fundal and corpus region) (figure 4 ). 

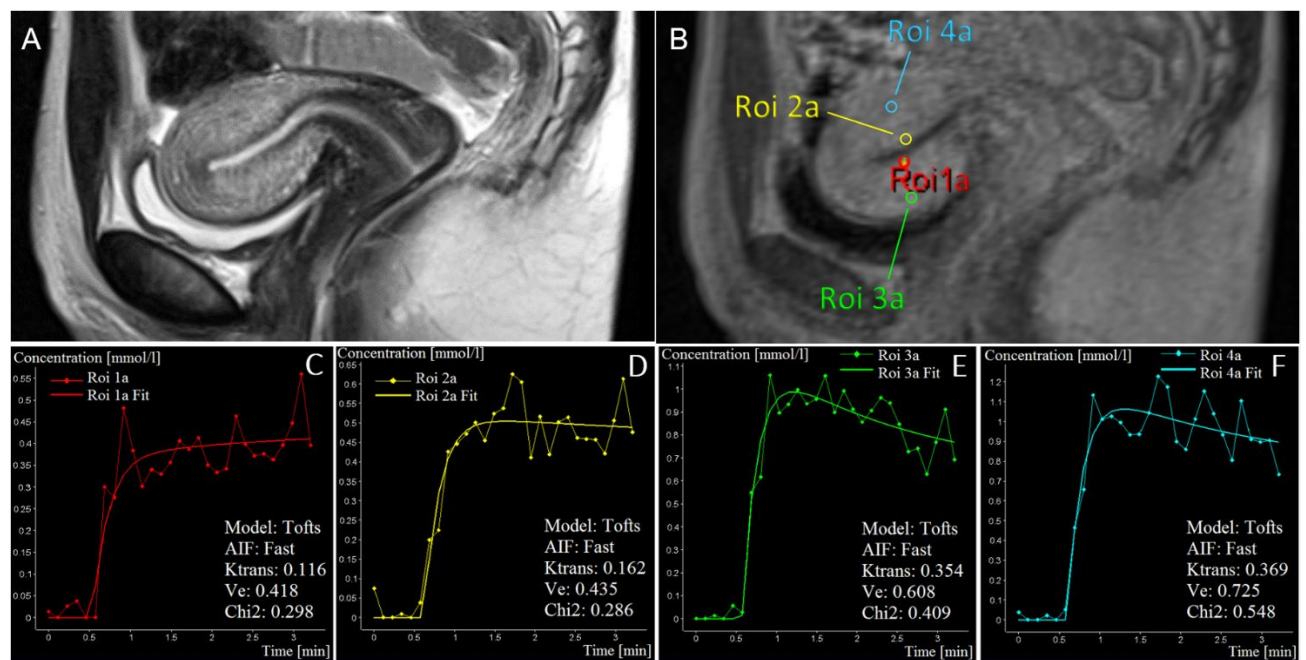

Figure 4: Example of perfusion assessment by dynamic contrast-enhanced magnetic resonance imaging (DCE-MRI) in the corpus and cervix uteri. A: Sagittal $\mathrm{T}_{2}$-weighted pelvic MRI-scan. B: Dynamic MRI-scan in order to assess perfusion Tissue 4D Calculations in different locations. The Regions of Interest (ROI) were placed at the anterior wall of the junctional zone (JZ) (ROI 1a), at the posterior wall of the JZ (ROI 2a), at the anterior wall of the outer myometrium (ROI $3 a$ ), at the posterior wall of the outer myometrium (ROI 4a), at the anterior wall of the inner third of the cervical stroma (ROI 1b), at the posterior wall of the inner third of the cervical stroma (ROI $2 b$ ), at the anterior wall of the outer two-thirds of the cervical stroma (ROI $3 \mathrm{~b}$ ) and at the posterior wall of the outer two-thirds of the cervical stroma (ROI 4b). C-J: Examples of concentration-time curves for respectively each ROI.

\subsubsection{Statistical analysis}

Mann-Whitney U-tests were performed in order to compare the uterine volumes between groups by means of IBM SPSS Statistics (version 23.0). All other statistical analyses were performed by means of the computer program SAS version 9.4. A significance level of $5 \%$ was used and no correction for multiple 
testing was applied.

Cohen's kappa coefficient was calculated in order to evaluate the concordance between the two readers for assessing the four perfusion parameters. Linear mixed models were used in order to investigate the effect of menstrual phase (for women not using hormonal contraception), the effect of parity and the effect of the location in uterine wall on the perfusion parameters iAUC/volume, $\mathrm{K}^{\text {trans }}, \mathrm{K}_{\mathrm{ep}}$ and Ve. The statistical model investigating the effect of phase in the nulliparous and primiparous non-users of hormonal contraception, included two main fixed effects and their interaction. The fixed effects were menstrual phase and the uterine location. In order to detect differences between groups, separate statistical models were constructed for nulliparous and primiparous women for each location including the fixed effect of hormonal contraception. The statistical models investigating the effect of uterine location, constructed for each group, contained the fixed effect of uterine location. The association between measurements of the same woman (e.g. measurements in different menstrual phases) was incorporated by means of a random intercept at woman level. A parsimonious model was obtained by backward elimination of interaction terms not statistically significant at a $5 \%$ level of significance. In order to normalize the data, statistical analyses were performed on the natural log transformed outcome data.

\subsection{Results}

The acquisition of the perfusion characteristics was accomplished successfully in 12 nulliparous non-users during the follicular phase, in 8 nulliparous non-users during the ovulatory and luteal phase, in 23 nulliparous users, in 5 primiparous non-users during the follicular phase, in 4 primiparous non-users during the luteal phase and in 33 primiparous users of contraception therapy. There was a high concordance between the two observers regarding the perfusion parameter assessment, as Cohen's kappa equated 0.87 for iAUC/volume, $\mathrm{K}^{\text {trans }}, \mathrm{K}_{\mathrm{ep}}$ and $\mathrm{Ve}$ together. No correlations were found between the perfusion parameters and the women's height and weight, age at menarche, gestity and parity status and smoker/non-smoker ( $p>0.050)$. 


\subsubsection{Uterine volumes}

The uterine volume in the nulliparous contraceptive users was significantly lower compared to the nulliparous non-users during the ovulatory $(p=0.002)$ and luteal ( $p=0.002$ ) phase (table 3 ). The uterine volume of these groups during the follicular phase was not significantly different $(p=0.101)$. No statistically significant differences were noticed in the uterine volumes between both groups of primiparous women or between the nulliparous and primiparous non-users of contraceptives $(p>0.050)$.

Table 3: Volumes of corpus uteri in nulliparous and primiparous non-users and users of hormonal contraception therapy during three menstrual phases. Data represents median (minimum - maximum). Data analysis was carried out on the natural log transformed outcome data. ${ }^{\square}$ : significantly different from the volume of nulliparous users of hormonal contraception.

\begin{tabular}{llcc} 
& & Volume corpus uteri $\left(\mathrm{cm}^{3}\right)$ & $\mathrm{n}$ \\
\hline Nulliparous non-users & Follicular phase & $100.27(49.02-183.24)$ & 17 \\
& Ovulatory phase & $107.81(58.86-197.48)^{口}$ & 14 \\
& Luteal phase & $105.91(55.40-212.20)^{口}$ & 14 \\
\hline Nulliparous users & & $70.34(27.36-156.05)$ & 30 \\
\hline Primiparous non-users & Follicular phase & $81.69(54.05-150.06)$ & 5 \\
& Luteal phase & $137.57(35.71-204.83)$ & 4 \\
\hline Primiparous users & & $91.99(30.29-187.51)$ & 37
\end{tabular}

\subsubsection{Perfusion parameters throughout the menstrual cycle}

The perfusion parameters assessed during the three menstrual phases in the nulliparous non-users of hormonal contraception were compared. $\mathrm{K}^{\text {trans }}$ and iAUC/volume were significantly different between the menstrual phases, whereas 
$K_{e p}$ and $V e$ were not $(p>0.050) . K^{\text {trans }}$ and iAUC/volume decreased over the menstrual cycle, from follicular to ovulatory to luteal phase (table 4).

Table 4: DCE-MRI perfusion parameters (iAUC/volume, $K^{\text {trans }}, K_{\text {ep }}$ and Ve) assessed in nulliparous and primiparous non-users of hormonal contraception during different menstrual phases. Data represents mean values over all measured locations. Data analysis was carried out on the natural log transformed outcome data. *: significantly different from the luteal phase of the same group; ${ }^{\Delta}$ : significantly different from the ovulatory phase of the same group; ${ }^{\circ}$ : significantly different from the same phase of the other group.

$K^{\text {trans }}$ significantly decreased during the ovulatory $(p=0.008)$ and luteal $(p=$ 0.027) phase compared to the follicular phase. Furthermore, iAUC/volume decreased during the luteal phase in comparison to the follicular $(p<0.001)$ and ovulatory ( $p=0.001)$ phase. In the primiparous non-users, the perfusion

\begin{tabular}{|c|c|c|c|c|c|}
\hline & & ¡AUC/volume & $\mathrm{K}^{\text {trans }}\left(\mathrm{min}^{-1}\right)$ & $K_{e p}\left(\min ^{-1}\right)$ & $\mathrm{Ve}$ \\
\hline \multirow{3}{*}{$\begin{array}{l}\text { Nulliparous non- } \\
\text { users }\end{array}$} & Follicular phase & $1.28 *$ & $0.82^{\Delta *}$ & $0.43^{\square}$ & 1.13 \\
\hline & Ovulatory phase & $1.23 *$ & 0.42 & 0.35 & 0.96 \\
\hline & Luteal phase & 0.68 & 0.55 & 0.59 & 1.12 \\
\hline \multirow{2}{*}{$\begin{array}{l}\text { Primiparous non- } \\
\text { users }\end{array}$} & Follicular phase & 1.27 & 0.52 & 0.38 & 1.46 \\
\hline & Luteal phase & 1.28 & 0.38 & 0.36 & 0.78 \\
\hline
\end{tabular}

parameters of the women in the follicular phase were not significantly different from those in the women in the luteal phase ( $p>0.050)$.

Furthermore, the perfusion parameters during the follicular and luteal phases in the nulliparous and primiparous women were also compared. This revealed that $\mathrm{K}_{\mathrm{ep}}$ was significantly higher in the nulliparous women than in the primiparous women during the follicular phase $(p=0.041)$, but not during the luteal phase ( $p$ $>0.050)$. The other perfusion parameters showed no significant differences between the nulliparous and the primiparous non-users. 
Anterior inner Posterior inner Anterior outer Posterior outer

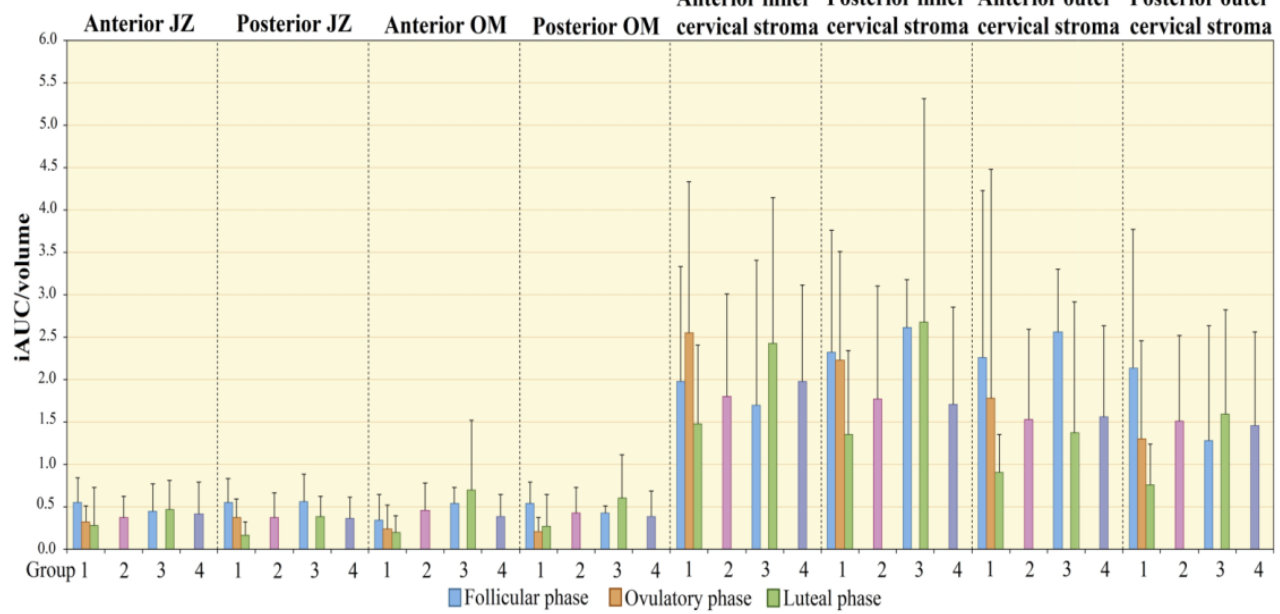

Figure 5: Mean (and SD) initial blood volumes (iAUC/volume) values of the junctional zone (JZ), outer myometrium (OM) and cervical inner third and outer two-thirds stroma. Initial blood volume was assessed in nulliparous non-users (group 1 ), nulliparous users (group 2), primiparous non-users (group 3) and primiparous users (group 4) of hormonal contraception during the menstrual cycle at different locations in the uterus and cervix.

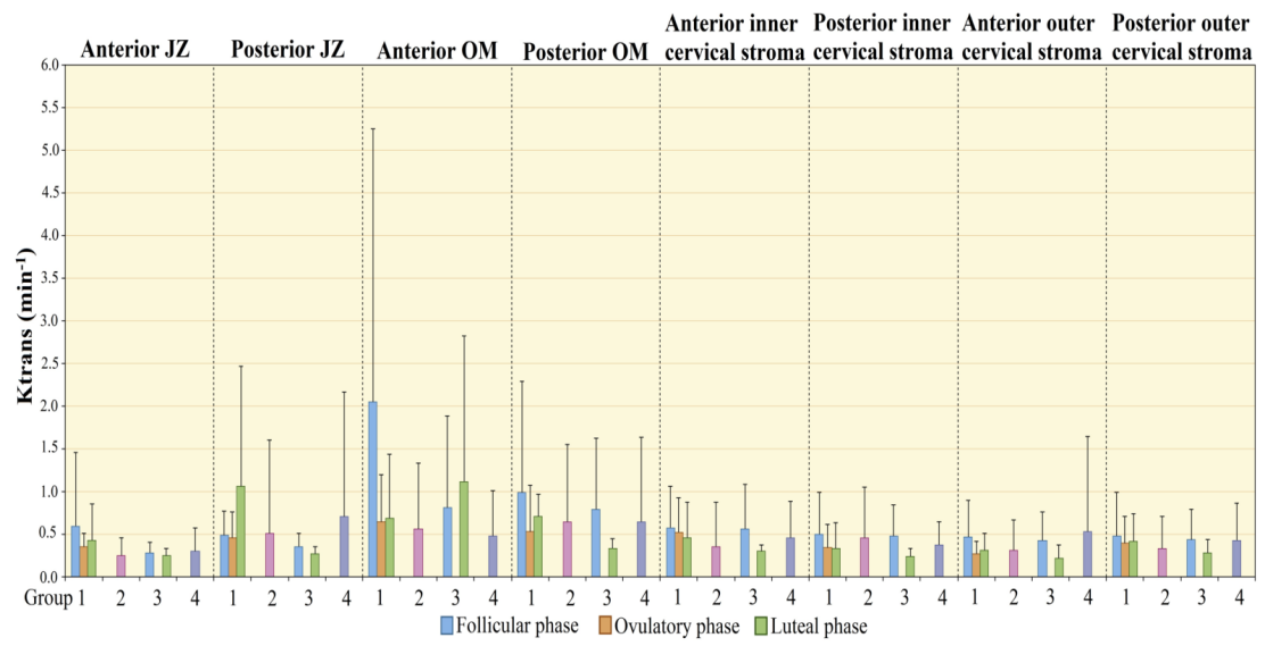

Figure 6: Mean (and SD) transfer constant (Ktrans) in the junctional zone (JZ), outer myometrium (OM) and cervical inner third and outer two-thirds stroma. The transfer constant was assessed in nulliparous non-users (group 1), nulliparous users (group 2 ), primiparous non-users (group 3) and primiparous users (group 4) of hormonal contraception during the menstrual cycle at different locations in the uterus and cervix. 


\subsubsection{Perfusion Parameters In Junctional Zone and Outer Myometrium}

The median, minimum and maximum of iAUC/volume, $K^{\text {trans }}, K_{e p}$ and $\mathrm{Ve}$ measurements are shown in respectively table 5, 6, 7 and 8 . There were no significant differences between the anterior and posterior uterine wall in either perfusion parameter for each group ( $p>0.050$ ), except for the nulliparous users of hormonal contraception. In this group, a significantly higher $K^{\text {trans }}$ was noticed in the posterior wall of the JZ compared to the anterior wall of the JZ $(p=0.041)$. 
Table 5: Initial blood volume (iAUC/volume) measurements in nulliparous and primiparous non-users and users of hormonal contraception in the anterior and posterior junctional zone (JZ) and outer myometrium (OM). 5A: Data represents median values(minimum - maximum). Data analysis was carried out on the natural log transformed outcome data. ${ }^{\Delta}$ : significantly different from anterior and posterior JZ and outer myometrium of the same group; $*$ : significantly different from nulliparous users in the same location; $\bullet$ : significantly different from primiparous users in the same location. 5B an overview of the standard deviation for each location in every group.

\section{$\underline{\mathbf{5 A}}$}

\begin{tabular}{|c|c|c|c|c|c|}
\hline iAUC/volume & & Anterior wall JZ ${ }^{\Delta}$ & Posterior wall JZ ${ }^{\Delta}$ & Anterior wall OM ${ }^{\Delta}$ & Posterior wall OM ${ }^{\triangle}$ \\
\hline \multirow[t]{3}{*}{ Nulliparous non-users } & Follicular phase & $0.56(0.14-1.33)$ & $0.48(0.22-1.08)$ & $0.23(0.00-0.99)$ & $0.53(0.16-0.92)$ \\
\hline & Ovulatory phase & $0.39(0.09-0.61)$ & $0.39(0.10-0.77)$ & $0.15(0.00-0.82)$ & * $0.20(0.00-0.56)$ \\
\hline & Luteal phase & $0.14(0.00-1.28)$ & $0.14(0.00-0.42)$ & $0.14(0.00-0.56)$ & $0.15(0.00-1.17)$ \\
\hline Nulliparous users * & & $0.29(0.03-1.17)$ & $0.29(0.00-1.64)$ & $0.44(0.01-1.50)$ & $0.35(0.00-1.14)$ \\
\hline \multirow[t]{2}{*}{ Primiparous non-users } & Follicular phase & $0.59(0.08-0.67)$ & $0.66(0.20-0.82)$ & $0.59(0.33-0.70)$ & $0.39(0.36-0.52)$ \\
\hline & Luteal phase & $0.36(0.17-0.86)$ & $0.33(0.17-0.64)$ & $0.36(0.11-1.64)$ & $0.42(0.20-1.19)$ \\
\hline Primiparous users $\bullet$ & & $0.29(0.09-2.14)$ & $0.29(0.00-1.07)$ & $0.36(0.00-0.87)$ & $0.35(0.00-1.19)$ \\
\hline
\end{tabular}




\begin{tabular}{|c|c|c|c|c|c|}
\hline iAUC/volume & & Anterior wall JZ ${ }^{\Delta}$ & $\underset{\Delta}{\text { Posterior wall JZ }}$ & $\underset{\Delta}{\text { Anterior wall OM }}$ & $\underset{\Delta}{\text { Posterior wall OM }}$ \\
\hline \multirow[t]{3}{*}{$\begin{array}{l}\text { Nulliparous } \\
\text { non-users }\end{array}$} & Follicular phase & $0,557( \pm 0,293)$ & $0,552( \pm 0,279)$ & $0,342( \pm 0,300)]$ & $0,540( \pm 0,252)$ \\
\hline & Ovulatory phase & $0,326( \pm 0,181)$ & $0,371( \pm 0,228)$ & $0,241( \pm 0,283)$ & $0,213( \pm 0,161)$ \\
\hline & Luteal phase & $0,278( \pm 0,449)$ & $0,168( \pm 0,156)$ & $0,196( \pm 0,205)$ & $0,275( \pm 0,375)$ \\
\hline $\begin{array}{l}\text { Nulliparous } \\
\text { users * }\end{array}$ & & $0,371( \pm 0,260)$ & $0,374( \pm 0,299)$ & $0,463( \pm 0,324)$ & $0,429( \pm 0,302)$ \\
\hline \multirow[t]{2}{*}{$\begin{array}{l}\text { Primiparous } \\
\text { non-users }\end{array}$} & Follicular phase & $0,449( \pm 0,319)$ & $0,563( \pm 0,323)$ & $0,540( \pm 0,187)$ & $0,427( \pm 0,084)$ \\
\hline & Luteal phase & $0,465( \pm 0,355)$ & $0,382( \pm 0,240)$ & $0,702( \pm 0,819)$ & $0,601( \pm 0,521)$ \\
\hline $\begin{array}{l}\text { Primiparous } \\
\text { users • }\end{array}$ & & $0,415( \pm 0,382)$ & $0,364( \pm 0,254)$ & $0,391( \pm 0,253)$ & $0,391( \pm 0,295)$ \\
\hline
\end{tabular}


Comparison of the perfusion parameters of the JZ with those of the outer myometrium demonstrated several differences. These differences were noticed only in the anterior uterine wall. In the nulliparous non-users, the $\mathrm{K}_{\mathrm{ep}}$ was significantly higher and $\mathrm{K}^{\text {trans }}$ significantly lower in the anterior $\mathrm{JZ}$ compared to the anterior outer myometrium ( $p=0.012$ and $p=0.050$, respectively). Furthermore, there was a trend towards a higher iAUC/volume in the anterior JZ wall compared to the anterior outer myometrium wall in this group $(p=0.060)$. In the nulliparous users, $\mathrm{K}^{\text {trans }}$ in the

anterior wall of the JZ was significantly lower than in the anterior outer myometrium wall $(p<0.001)$. Ve in the anterior $\mathrm{JZ}$ wall in the primiparous users was significantly lower compared to the anterior wall of the outer myometrium ( $p$ $=0.012$ ).

Table 6: Transfer constant $\left(K^{\text {trans }}\right)$ measurements in nulliparous and primiparous non-users and users of hormonal contraception in the anterior and posterior junctional zone (JZ) and outer myometrium (OM). 6A: Data represents median values(minimum - maximum). Data analysis was carried out on the natural log transformed outcome data. $\square$ : significantly different from posterior JZ of the same group, $\Delta$ : significantly different from anterior OM of the same group; *: significantly different from nulliparous nonusers in the same location. 6B an overview of the standard deviation for each location in every group. 


\begin{tabular}{|c|c|c|c|c|c|}
\hline $\begin{array}{l}\text { Ktrans (min- } \\
\text { 1) }\end{array}$ & & Anterior wall JZ & Posterior wall JZ & $\underset{\Delta}{\text { Anterior wall OM }}$ & $\begin{array}{l}\text { Posterior wall } \\
\text { OM }\end{array}$ \\
\hline \multirow[t]{3}{*}{$\begin{array}{l}\text { Nulliparous } \\
\text { non-users }\end{array}$} & Follicular phase & $0,593( \pm 0,865)$ & $0,484( \pm 0,285)$ & $\begin{array}{c}{ }^{\Delta} 2,051( \pm \\
3,203)\end{array}$ & $0,990( \pm 1,297)$ \\
\hline & $\begin{array}{l}\text { Ovulatory } \\
\text { phase }\end{array}$ & $0,351( \pm 0,164)$ & $\begin{array}{l}\Delta \quad 0,454( \pm 0,306) \\
*\end{array}$ & $* 0,641( \pm 0,555)$ & $0,528( \pm 0,545)$ \\
\hline & Luteal phase & $0,430( \pm 0,424\}$ & $1,061( \pm 1,406)$ & $0,683 \pm(0,754)$ & $0,710 \pm(0,253)$ \\
\hline $\begin{array}{l}\text { Nulliparous } \\
\text { users * }\end{array}$ & & $0,247( \pm 0,214)$ & $\Delta \quad 0,509( \pm 1,090)$ & $0,558( \pm 0,774)$ & $0,641( \pm 0,907)$ \\
\hline \multirow[t]{2}{*}{$\begin{array}{l}\text { Primiparous } \\
\text { non-users }\end{array}$} & Follicular phase & $0,276( \pm 0,133)$ & $0,357( \pm 0,149)$ & $0,812( \pm 1,075)$ & $0,793( \pm 0,834)$ \\
\hline & Luteal phase & $0,247( \pm 0,091)$ & $0,269( \pm 0,082)$ & $1,119( \pm 1,699)$ & $0,337( \pm 0,110)$ \\
\hline $\begin{array}{l}\text { Primiparous } \\
\text { users }\end{array}$ & & $0,303( \pm 0,271)$ & $0,703( \pm 1,462)$ & $0,481( \pm 0,529)$ & $0,647( \pm 0,984)$ \\
\hline
\end{tabular}




\begin{tabular}{|c|c|c|c|c|c|}
\hline $\mathrm{K}^{\text {trans }}\left(\min ^{-1}\right)$ & & Anterior wall JZ & Posterior wall JZ & Anterior wall $\mathrm{OM}^{\Delta}$ & Posterior wall OM \\
\hline \multirow[t]{3}{*}{ Nulliparous non-users } & Follicular phase & $0.34(0.20-3.30)$ & $0.46(0.19-1.12)$ & $0.43(0.20-8.72)$ & $0.47(0.08-4.10)$ \\
\hline & Ovulatory phase & $0.24(0.16-0.58)$ & $\begin{array}{l}\Delta 0.27(0.14-0.97) \\
*\end{array}$ & $* 0.45(0.11-1.72)$ & $0.36(0.10-1.79)$ \\
\hline & Luteal phase & $\begin{array}{c}0.19(0.14- \\
1.32)\end{array}$ & $\begin{array}{c}0.63(0.16- \\
4.40)\end{array}$ & $0.36(0.10-2.17)$ & $0.74(0.32-1.12)$ \\
\hline Nulliparous users * & & $0.17(0.03-1.05)$ & $\triangle 0.20(0.03-7.18)$ & $0.31(0.02-5.40)$ & $0.33(0.06-5.60)$ \\
\hline \multirow[t]{2}{*}{$\begin{array}{l}\text { Primiparous non- } \\
\text { users }\end{array}$} & Follicular phase & $0.28(0.13-0.45)$ & $0.35(0.16-0.54)$ & $0.42(0.14-2.72)$ & $0.46(0.11-2.20)$ \\
\hline & Luteal phase & $0.24(0.15-0.36)$ & $0.29(0.15-0.35)$ & $0.33(0.14-3.66)$ & $0.34(0.21-0.45)$ \\
\hline Primiparous users & & $0.19(0.06-1.10)$ & $0.33(0.08-2.91)$ & $0.25(0.07-6.89)$ & $0.31(0.08-3.69)$ \\
\hline
\end{tabular}




\subsubsection{Perfusion Parameters in Nulliparous And Primiparous Non- users And Users Of Hormonal Contraception}

In the nulliparous women on hormonal contraception, $\mathrm{K}^{\text {trans }}$ was lower in the anterior and posterior wall of the JZ than in the non-users of hormonal contraception ( $p=0.001$ and $p=0.013$, respectively) (table 6 ). $K_{e p}$ and iAUC/volume in the anterior wall of the outer myometrium was higher in the nulliparous users of hormonal contraception compared to the non-users ( $p=$ 0.049 and $p=0.001$ ) (table 7 and 5).

Table 7: Reflux constant $\left(K_{\mathrm{ep}}\right)$ measurements in nulliparous and primiparous non-users and users of hormonal contraception in the anterior and posterior junctional zone (JZ) and outer myometrium (OM). Data represents median values(minimum - maximum). Data analysis was carried out on the natural log transformed outcome data. ${ }^{\Delta}$ : significantly different from anterior OM of the same group; * significantly different from nulliparous users in the same location. 7B: an overview of the standard deviation for each location in every group. 


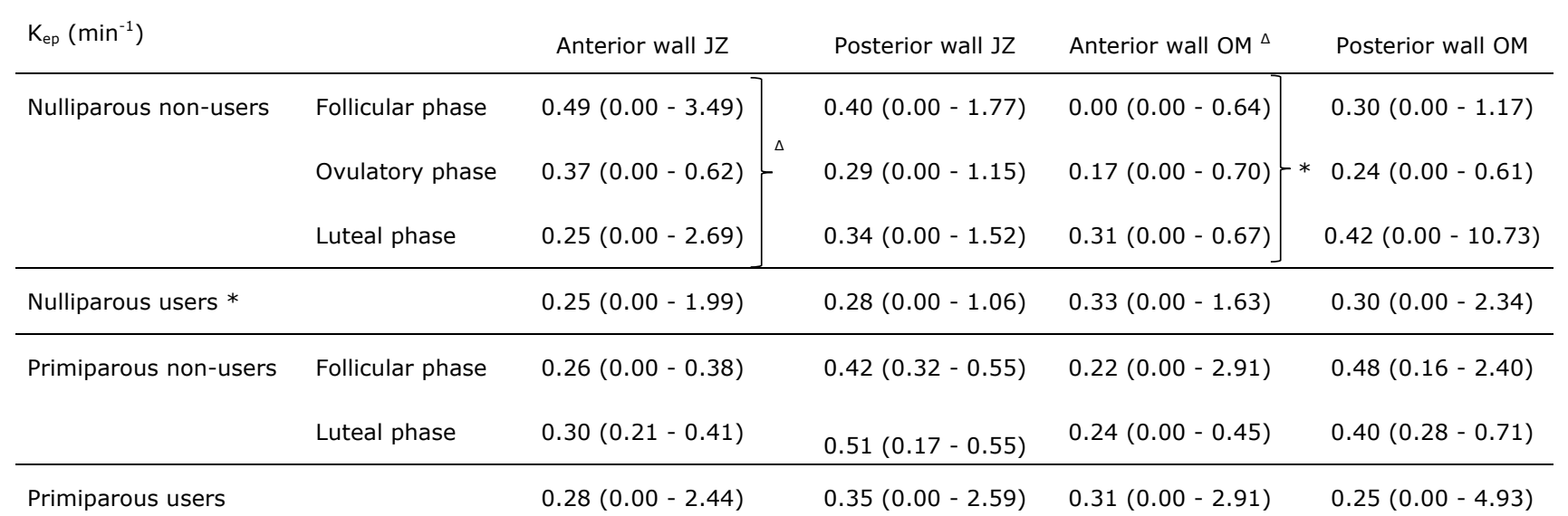




\begin{tabular}{|c|c|c|c|c|c|c|c|}
\hline $\mathrm{K}_{\mathrm{ep}}(\min -1)$ & & Anterior wall JZ & & Posterior wall JZ & Anterior wall OM ${ }^{\triangle}$ & & Posterior wall OM \\
\hline \multirow[t]{3}{*}{$\begin{array}{l}\text { Nulliparous } \\
\text { non-users }\end{array}$} & Follicular phase & $0,719( \pm 0,895)$ & & $0,462( \pm 0,475)$ & $0,213( \pm 0,251)]$ & & $0,350( \pm 0,380)$ \\
\hline & Ovulatory phase & $0,327( \pm 0,238)$ & $\Delta$ & $0,375( \pm 0,371)$ & $0,226( \pm 0,287)$ & * & $0,218( \pm 0,226)$ \\
\hline & Luteal phase & $0,490( \pm 0,904)$ & & $0,480( \pm 0,546)$ & $0,288( \pm 0,272)$ & & $1,681( \pm 3,678)$ \\
\hline $\begin{array}{l}\text { Nulliparous } \\
\text { users * }\end{array}$ & & $0,325( \pm 0,317)$ & & $0,309( \pm 0,244)$ & $0,398( \pm 0,358)$ & & $0,419( \pm 0,463)$ \\
\hline \multirow[t]{2}{*}{$\begin{array}{l}\text { Primiparous } \\
\text { non-users }\end{array}$} & Follicular phase & $0,190( \pm 0,178)$ & & $0,422( \pm 0,092)$ & $0,726( \pm 1,238)$ & & $0,890( \pm 0,909)$ \\
\hline & Luteal phase & $0,305( \pm 0,089)$ & & $0,434( \pm 0,180)$ & $0,236( \pm 0,189)$ & & $0,449( \pm 0,201)$ \\
\hline $\begin{array}{l}\text { Primiparous } \\
\text { users }\end{array}$ & & $0,358( \pm 0,421)$ & & $0,479( \pm 0,491)$ & $0,437( \pm 0,560)$ & & $0,444( \pm 0,859)$ \\
\hline
\end{tabular}


In the primiparous women, $\mathrm{Ve}$ in the anterior wall of the $\mathrm{JZ}$ was significantly lower in the users than in the non-users of hormonal contraception $(p=0.044)$ (table 8$)$. iAUC/volume in the anterior wall of the outer myometrium decreased in the primiparous users of hormonal contraception compared to the non-users $(p=0.036)$.

Table 8: Interstitial volume (Ve) measurements in nulliparous and primiparous non-users and users of hormonal contraception in the anterior and posterior junctional zone (JZ) and outer myometrium (OM). Data represents medianvalues(minimum maximum). Data analysis was carried out on the natural log transformed outcome data. ${ }^{\Delta}$ : significantly different from anterior wall outer myometrium of the same group; $\bullet$ : significantly different from primiparous users in the same location.

8B: an overview of the standard deviation for each location in every group.

\section{$\underline{8 A}$}

\begin{tabular}{|c|c|c|c|c|c|}
\hline Ve & & Anterior wall JZ & Posterior wall JZ & $\underset{\Delta}{\operatorname{Anterior} \text { wall OM }}$ & Posterior wall OM \\
\hline \multirow[t]{3}{*}{ Nulliparous non-users } & Follicular phase & $0.70(0.48-1.78)$ & $0.81(0.47-5.43)$ & $\begin{array}{c}0.88(0.00- \\
1.63)\end{array}$ & $0.88(0.55-1.90)$ \\
\hline & Ovulatory phase & $0.79(0.42-1.59)$ & $0.85(0.46-2.10)$ & $\begin{array}{c}0.89(0.09- \\
3.04)\end{array}$ & $0.79(0.53-3.99)$ \\
\hline & Luteal phase & $0.69(0.05-1.89)$ & $0.76(0.00-2.22)$ & $\begin{array}{l}0.79(0.00- \\
2.40)\end{array}$ & $0.93(0.08-2.00)$ \\
\hline Nulliparous users & & $\begin{array}{l}0.68(0.00- \\
82.66)\end{array}$ & $0.66(0.00-1.76)$ & $\begin{array}{l}0.76(0.00- \\
4.08)\end{array}$ & $0.79(0.00-4.31)$ \\
\hline \multirow[t]{2}{*}{$\begin{array}{l}\text { Primiparous non- } \\
\text { users }\end{array}$} & Follicular phase & $\begin{array}{c}0.92(0.48- \\
14.13)\end{array}$ & $0.85(0.52-0.99)$ & $\begin{array}{l}0.94(0.69- \\
2.28)\end{array}$ & $0.91(0.70-1.04)$ \\
\hline & Luteal phase & $0.83(0.63-0.98)$ & $0.61(0.52-0.94)$ & $\begin{array}{c}0.91(0.70- \\
1.22)\end{array}$ & $0.80(0.63-0.92)$ \\
\hline Primiparous users $\bullet$ & & $0.68(0.31-2.01)$ & $0.66(0.33-2.24)$ & $\begin{array}{c}0.80(0.40- \\
1.84)\end{array}$ & $0.80(0.00-4.37)$ \\
\hline
\end{tabular}




\begin{tabular}{llcccc} 
Ve & Anterior wall JZ & Posterior wall JZ & $\begin{array}{c}\text { Anterior wall OM } \\
\Delta\end{array}$ & $\begin{array}{c}\text { Posterior wall } \\
\text { OM }\end{array}$ \\
\hline $\begin{array}{l}\text { Nulliparous } \\
\text { non-users }\end{array}$ & $\begin{array}{l}\text { Follicular phase } \\
\text { Ovulatory } \\
\text { phase }\end{array}$ & $0,783( \pm 0,347)$ & $1,213( \pm 1,385)$ & $0,918( \pm 0,444)$ & $0,940( \pm 0,378)$ \\
& $0,900( \pm 0,444)$ & $0,977( \pm 0,534)$ & $1,149( \pm 0,945)$ & $1,446( \pm 1,247)$ \\
& Luteal phase & $0,890( \pm 0,630)$ & $0,883( \pm 0,657)$ & $0,903( \pm 0,701)$ & $1,090( \pm 0,618)$ \\
\hline $\begin{array}{l}\text { Nulliparous } \\
\text { users }\end{array}$ & & $\begin{array}{c}2,142( \pm \\
10,376)\end{array}$ & $0,680( \pm 0,381)$ & $0,880( \pm 0,617)$ & $0,933( \pm 0,787)$ \\
\hline $\begin{array}{l}\text { Primiparous } \\
\text { non-users }\end{array}$ & Follicular phase & $3,497( \pm 5,946)$ & $0,822( \pm 0,188)$ & $1,321( \pm 0,677)$ & $0,882( \pm 0,133)$ \\
& Luteal phase & $0,818( \pm 0,150)$ & $0,668( \pm 0,190)$ & $0,936( \pm 0,213)$ & $0,786( \pm 0,119)$ \\
\hline $\begin{array}{l}\text { Primiparous } \\
\text { users }\end{array}$ & & $0,776( \pm 0,389)$ & $0,724( \pm 0,348)$ & $0,898( \pm 0,407)$ & $1,000( \pm 0,875)$
\end{tabular}




\subsection{Discussion}

To our knowledge, this study is the first in literature comparing DCE-MRI perfusion characteristics of the $\mathrm{JZ}$ and the outer myometrium in young healthy nulliparous and primiparous women, subdivided by their use of contraception therapy. Moreover, we used acquisition parameters with $1.5 \mathrm{~mm}$ slice thickness (3D FLASH) and DCE within three seconds per measurement over a time period of more than three minutes on a $1.5 \mathrm{~T}$ MRI, most commonly used in daily clinical practice. These data could be useful in future attempts in assisted reproductive treatments or in detecting pathological uterine conditions.

The first description of healthy myometrial enhancement by 1.5T DCE-MRI was reported by Yamashita et al. in 1993, who investigated 27 healthy women (14). Another study assessed physiological microvascular perfusion of normal myometrium in 62 women of reproductive age using DCE-MRI, in which a 1.5T MRI scanner and a slice thickness of $5 \mathrm{~mm}$ was used (9). However, this study made no distinction based on the parity or the use of hormonal contraception and the women were investigated only once during their menstrual cycle.

In our study, nulliparous women who used hormonal contraceptives had a smaller uterine volume than nulliparous women who did not use hormonal contraceptives, during the ovulatory and luteal phase. Merz et al. investigated uterine volumes on transvaginal ultrasound in a group consisting of 52 nulliparous, 52 primiparous and 53 multiparous women, and detected a parity-related enlargement in uterine size (15). This result could not be derived from the measurements of our study.

We focused on investigating the perfusion of the $\mathrm{JZ}$ and outer myometrium by assessing the following physiological parameters: initial blood volume (iAUC/volume), transfer constant $\left(K^{\text {trans }}\right)$, efflux constant $\left(K_{e p}\right)$ and interstitial volume (Ve). Previously is demonstrated that the uterine myometrial wall contains a discontinuity and that the inner third contains a different morphology than the outer two-thirds. This inner third is known as the junctional zone. Investigations on uterine specimens revealed a higher vascular perfusion rate in the JZ compared to the outer myometrium (16). This finding correlates with the results of our study which show a higher reflux constant $\left(K_{e p}\right)$ in nullipara non-users at the anterior $J Z$ 
compared to the anterior outer myometrium. Furthermore, histological analysis studies on myometrial tissue found a threefold increase in percentage of nuclear area and cellular density, a decrease in extracellular matrix and a lower water content in the inner myometrium in comparison with the outer myometrium (1719). These findings are also in concordance with our results, which indicate a lower transfer constant $\left(\mathrm{K}^{\text {trans }}\right)$ in nulliparous users of hormonal contraception and a lower interstitial volume (Ve) in primiparous users of hormonal contraception at the anterior JZ than at the anterior outer myometrium. Our results confirm the physiological differences between the inner third and the outer two-thirds of the myometrium, with dissimilar microvascular characteristics in both layers. These findings are as expected as a high $\mathrm{JZ}$ perfusion (due to higher transfer constant, lower efflux constant and higher initial blood volume than in the outer myometrium) in nulliparous non-users of contraceptives is believed to be involved in uterine contraction and subsequent transfer of spermatozoa and in embryo implantation $(20,21)$.

It is known that, in women of reproductive age, the $\mathrm{JZ}$ demonstrated cyclic variations in blood flow throughout the menstrual cycle. This is already demonstrated by means of 3D power Doppler angiography and more recently also by means of DCE-MRI (9). In our study, the highest initial blood volume in the JZ was also found during the follicular phase, followed by a decrease in initial blood volume during the luteal phase. These findings can be explained by the development of small vessels, such as spiral arteries, in the inner myometrium during the follicular phase $(1,22)$. In addition, just before ovulation, estradiol serum levels and a transient increase in myometrial basal tone and uterine contractility could also explain the higher blood volume $(23,24)$. Doppler ultrasound differences in internal myometrial perfusion during the menstrual cycle are well described and are believed to be involved in migration of spermatozoa (contraction) and in embryo implantation. Raine-Fenning et al. characterized, based on Doppler ultrasound findings, an increased vascularisation in the JZ during the proliferative (follicular) phase, peaking approximately three days prior to ovulation before decreasing to a nadir 5 days post-ovulation (20).

The study by Thomassin-Naggara et al. examined perfusion of the inner (JZ) and outer myometrium in 62 women of reproductive age (31 women in the 
proliferative phase and 31 women in the luteal phase) by DCE-MRI (used MRI acquisition characteristics: repetition time/echo time: $27 / 2.24 \mathrm{~ms}$; flip angle: $80^{\circ}$; slice thickness: $5 \mathrm{~mm}$; number of slices: 3 ; excitations: 1 ; field of view: 400$200 \mathrm{~mm}$; interpolated matrix $256 \times 134$; bandwidth (BW): 300) and they found behavioral differences in inner myometrium in the different menstrual phases, whereas no differences in the outer myometrium were demonstrated (9). In the $\mathrm{JZ}$, they noticed a higher tissue blood flow $(\mathrm{F})$ and blood volume fraction $(\mathrm{Vb})$ during the follicular phase than during the luteal phase. Nevertheless, they did not observe differences between those phases for permeability-surface area product (PS, which is correlated with $\mathrm{K}^{\text {trans }}$, Ve and $\mathrm{K}_{\mathrm{ep}}$ ) and interstitial volume $(\mathrm{Ve})$ in the JZ (9). Thomassin-Naggara and colleagues performed the study on women of all ages (whereas in our study the age limits were between 18 and 35 years), made no distinction between nulliparous and multipara women and between women who used contraception therapy and those who did not, and MRI examination was performed once in a woman's menstrual cycle.

The findings obtained with Doppler ultrasound and DCE-MRI, including our study and the study by Thomassin-Naggara et al., are thus consistent. However, DCEMRI is more sensitive than Doppler ultrasound in the evaluation of myometrial flow, especially at the edges of the uterus and for retroverted uteri $(2,25)$. In addition, DCE-MRI allows quantification of perfusion parameters, which is not obvious in Doppler ultrasound.

A limitation of our study is the low number of participating women, especially in the group of primiparous non-users of contraception therapy. Another limitation is that not all women underwent three MRI investigations per menstrual cycle, the nulliparous women were scanned three times during the menstrual cycle, whereas the primiparous women were investigated once. In addition, although this study included healthy nulliparous women, it is unknown if they are to have any reproductive challenges in the future.

In conclusion, this study provides DCE-MRI perfusion parameters (iAUC/volume, $\mathrm{K}^{\text {trans }}, \mathrm{K}_{\mathrm{ep}}$ and $\mathrm{Ve}$ ) of the $\mathrm{JZ}$ and outer myometrium in a healthy population of nulliparous and primiparous women who use and did not use hormonal contraception. Our data showed that in nulliparous non-users of contraception 
therapy, especially the transfer constant ( $\left.\mathrm{K}^{\text {trans}}\right)$ and the initial uterine blood volume (iAUC/volume), demonstrated cyclic changes according to the menstrual cycle. In addition, the use of hormonal contraceptives led often to a reduction in transfer constant $\left(K^{\text {trans }}\right)$ in the $\mathrm{JZ}$. These perfusion characteristics of healthy $\mathrm{JZ}$ and outer myometrium can be expected to aid the diagnosis and/or therapeutic intervention of conditions of the female reproductive system and to characterize the myometrium, especially the $\mathrm{JZ}$, in the context of assisted reproductive therapy in infertile patients. 


\subsection{References}

1. Chard T, Grudzinskas JG. The Uterus - Anatomy of the Uterus - Nutrition; p. 29-39: 1994.

2. Raine-Fenning NJ, Campbell BK, Kendall NR, Clewes JS, Johnson IR. Endometrial and subendometrial perfusion are impaired in women with unexplained subfertility. Hum Reprod 2004;19(11):2605-2614.

3. Girling JE, Rogers PA. Recent advances in endometrial angiogenesis research. Angiogenesis $2005 ; 8(2): 89-99$.

4. Benagiano G, Brosens I, Carrara S. Adenomyosis: new knowledge is generating new treatment strategies. Womens Health (Lond Engl) 2009;5(3):297-311.

5. Schreinemacher $\mathrm{MH}$, Backes WH, Slenter JM, et al. Towards endometriosis diagnosis by gadofosveset-trisodium enhanced magnetic resonance imaging. PLoS One $2012 ; 7(3): \mathrm{e} 33241$.

6. Sala E, Rockall A, Rangarajan D, Kubik-Huch RA. The role of dynamic contrast-enhanced and diffusion weighted magnetic resonance imaging in the female pelvis. Eur J Radiol $2010 ; 76(3): 367-385$.

7. Steer CV, Tan SL, Mason BA, Campbell S. Midluteal-phase vaginal color Doppler assessment of uterine artery impedance in a subfertile population. Fertil Steril 1994;61(1):53-58.

8. Reynolds LP, Grazul-Bilska AT, Redmer DA. Angiogenesis in the female reproductive organs: pathological implications. Int J Exp Pathol 2002;83(4):151-163.

9. Thomassin-Naggara I, Balvay D, Cuenod CA, Daraï E, Marsault C, Bazot M. Dynamic contrast-enhanced MR imaging to assess physiologic variations of myometrial perfusion. Eur Radiol 2010;20(4):984-994.

10. Heye T, Boll DT, Reiner CS, Bashir MR, Dale BM, Merkle EM. Impact of precontrast T1 relaxation times on dynamic contrast-enhanced MRI pharmacokinetic parameters: T1 mapping versus a fixed T1 reference value. J Magn Reson Imaging 2014;39(5):1136-1145.

11. Tofts PS. Modeling tracer kinetics in dynamic Gd-DTPA MR imaging. J Magn Reson Imaging $1997 ; 7(1): 91-101$.

12. Goldstein SR, Horii SC, Snyder JR, Raghavendra BN, Subramanyam B. Estimation of nongravid uterine volume based on a nomogram of gravid uterine volume: its value in gynecologic uterine abnormalities. Obstet Gynecol 1988;72(1):86-90. 
13. Thomassin-Naggara I, Siles P, Balvay D, Cuenod CA, Carette MF, Bazot M. MR perfusion for pelvic female imaging. Diagn Interv Imaging 2013;94(12):1291-1298.

14. Yamashita Y, Harada M, Sawada T, Takahashi M, Miyazaki K, Okamura H. Normal uterus and FIGO stage I endometrial carcinoma: dynamic gadolinium-enhanced MR imaging. Radiology $1993 ; 186(2): 495-501$.

15. Merz E, Miric-Tesanic D, Bahlmann F, Weber G, Wellek S. Sonographic size of uterus and ovaries in pre- and postmenopausal women. Ultrasound Obstet Gynecol 1996;7(1):38-42.

16. Lee JK, Gersell DJ, Balfe DM, Worthington JL, Picus D, Gapp G. The uterus: in vitro MRanatomic correlation of normal and abnormal specimens. Radiology 1985;157(1):175-179.

17. Scoutt LM, Flynn SD, Luthringer DJ, McCauley TR, McCarthy SM. Junctional zone of the uterus: correlation of MR imaging and histologic examination of hysterectomy specimens. Radiology $1991 ; 179(2): 403-407$.

18. McCarthy S, Scott G, Majumdar S, et al. Uterine junctional zone: MR study of water content and relaxation properties. Radiology 1989;171(1):241-243.

19. Brown HK, Stoll BS, Nicosia SV, et al. Uterine junctional zone: correlation between histologic findings and MR imaging. Radiology $1991 ; 179(2): 409-413$.

20. Raine-Fenning NJ, Campbell BK, Kendall NR, Clewes JS, Johnson IR. Quantifying the changes in endometrial vascularity throughout the normal menstrual cycle with three-dimensional power Doppler angiography. Hum Reprod 2004;19(2):330-338.

21. Kido A, Togashi K, Nakai A, Kataoka ML, Koyama T, Fujii S. Oral contraceptives and uterine peristalsis: evaluation with MRI. J Magn Reson Imaging 2005;22(2):265-270.

22. Blackwell PM, Fraser IS. A morphometric and ultrastructural study of the microvessels of the functional zone of normal human endometrium with some notions on possible secretory functions of the endothelial cells. Asia Oceania J Obstet Gynaecol 1988;14(2):233-250.

23. Ijland MM, Evers JL, Dunselman GA, van Katwijk C, Lo CR, Hoogland HJ. Endometrial wavelike movements during the menstrual cycle. Fertil Steril 1996;65(4):746-749.

24. Kunz G, Beil D, Deininger H, Wildt L, Leyendecker $G$. The dynamics of rapid sperm transport through the female genital tract: evidence from vaginal sonography of uterine peristalsis and hysterosalpingoscintigraphy. Hum Reprod 1996;11(3):627-632. 
25. Steer CV, Campbell S, Pampiglione JS, Kingsland CR, Mason BA, Collins WP. Transvaginal colour flow imaging of the uterine arteries during the ovarian and menstrual cycles. Hum Reprod 1990;5(4):391-395. 
